\title{
Obituary
}

\section{Robert M. Goldwyn - The end of an era!}

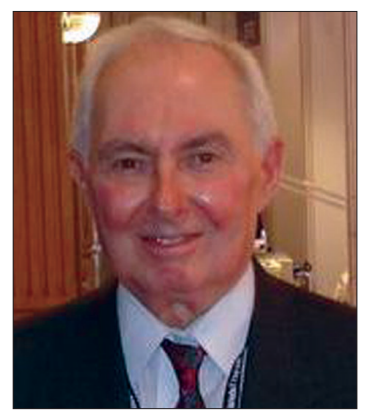

Robert M. Goldwyn

Everyday the mighty sun rises and after energizing the green earth, almost unnoticed, and without any fuss, sets in the far horizon. Across seven seas, again unnoticed and silently, yet another sun has set, after doing what he did best - stimulate, uplift and energize the world of Plastic Surgery. Robert M. Goldwyn, the grand old man of Plastic Surgery, slipped into the pages of history on March 23, 2010 in Brookline, Massachusetts, USA.

Robert Goldwyn was a human being par excellence, an accomplished surgeon, an outstanding teacher and the iconic editor of the leading journal Plastic and Reconstructive Surgery for over a quarter of a century. His bold and brutally frank editorials were a clarion call to lesser mortals in the field to attempt a course correction, whenever he felt they were erring or being led astray. His unforgettable masterpiece - The Unfavourable Results in Plastic Surgery - is a collector's special with each chapter identifying complications and problems associated with a particular procedure and then suggesting steps and precautions to avoid them. He also authored Avoidance and Treatment (now in its third edition), Reconstructive Surgery of the Breast, Long-Term Results in Plastic and Reconstructive Surgery, and Reduction Mammaplasty. He also penned The Patient and the Plastic Surgeon (two editions) and The Operative Note, a collection of his editorials, as well as a book for the general public: Beyond Appearance: Reflections of a Plastic Surgeon. With J. Saxe as translator, he wrote an introduction to G. Baronio's Degli Innesti Animali (On Grafting in Animals). He also wrote the introduction for the first complete English translation by J. H. Thomas of G. Tagliacozzi's De curtorum chirurgia per insitionem, 1597 (On the Surgical Restoration of Defects by Grafting, a facsimile edition). A link to all his published papers <http://www. ncbi.nlm.nih.gov/pubmed?term $=$ Goldwyn $+R+M \% 5$ Baut hor\%5D\&cmd = detailssearch $>$
Robert Goldwyn did his internship and residency in general surgery at the Peter Bent Brigham Hospital in Boston from 1956 to 1961. During this period he was the Harvey Cushing Fellow in Surgery at the Peter Bent Brigham Hospital. His plastic surgical training was at the University of Pittsburgh Medical Center from 1961 to 1963 under William White. He returned to Boston and ultimately became Senior Surgeon at the Peter Bent Brigham Hospital, Chief of Plastic Surgery at Beth Israel Hospital, and Clinical Professor of Surgery at Harvard Medical School.

Dr. Goldwyn served as President of the Massachusetts Society of Plastic Surgeons, the New England Society of Plastic Surgery, the American Association of Plastic Surgeons, which made him an Honorary Fellow, and the Harvard Medical Alumni Association. In 1972 he founded the National Archives of Plastic Surgery, housed at Countway Medical Library, and served as Chairman of the Archives Committee of the Plastic Surgery Educational Foundation.

He was a founding member of Physicians for Social Responsibility and wrote articles on world peace, opposition to chemical and biological warfare, and medical ethics.

He had been a visiting professor to more than 70 institutions, universities, and hospitals in his own country and abroad and was an honorary member of more than a dozen national and international societies of plastic surgery. His other awards included the Dieffenbach Medal, the Honorary Kazanjian Lectureship, Clinician of the Year of the American Association of Plastic Surgeons, and the Special Achievement Award and the Presidential Citation of the American Society of Plastic and Reconstructive Surgeons. 
Robert Goldwyn is survived by his loving wife Tatyana (Tanya), his children and grandchildren. We pray to God to give them strength in this hour of grief. The Association of Plastic Surgeons of India will always remain grateful to him for his guidance and care, which he showered on our members whenever they interacted with him.
To me, personally, he set the gold standard for editing a Plastic Surgery journal; a standard we all strive to achieve throughout our life.

\section{Surajit Bhattacharya}

Editor, Indian Journal of Plastic Surgery E-mail: surajitb@sancharnet.in 